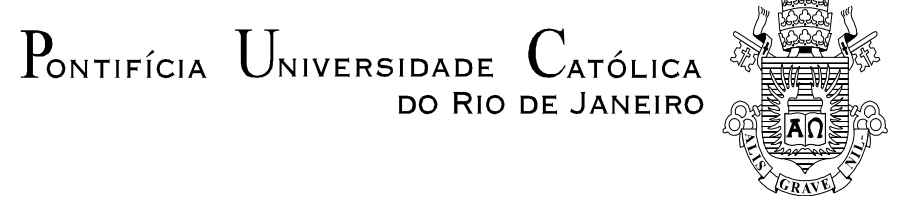

Danrlei de Freitas Azevedo

Morte da Arte:
a aparência estética desencantada

Tese de Doutorado

Tese apresentada ao Programa de Pós-Graduação em História Social da Cultura do Departamento de História da PUC-Rio como parte dos requisitos parciais para obtenção do título de Doutor em História.

Orientador: Prof. Luiz de França Costa Lima Filho 


\title{
Danrlei de Freitas Azevedo
}

\author{
Morte da Arte: \\ a aparência estética desencantada
}

\begin{abstract}
Tese apresentada ao Programa de Pós-Graduação em História Social da Cultura do Departamento de História da PUC-Rio como parte dos requisitos parciais para obtenção do título de Doutor em História.

Aprovada pela Comissão Examinadora abaixo assinada.
\end{abstract}

\section{Prof. Luiz de França Costa Lima Filho}

Orientador

Departamento de História - PUC-Rio

\section{Prof. Alberto de Almeida Prado Tassinari Departamento de Filosofia \\ USP}
Prof. Ricardo José Corrêa Barbosa
Departamento de Filosofia
UERJ

Prof. Ronaldo Brito Fernandes

Departamento de História

PUC-Rio

\section{Prof. Luiz Camillo Dollabela Portella Osório de Almeida \\ Departamento de Filosofia \\ PUC-Rio}

Prof. Nizar Messari

Vice-Decano de Pós-Graduação do Centro de Ciências Sociais

PUC-Rio

Rio de Janeiro, 19 de dezembro de 2008. 
Todos os direitos reservados. É proibida a reprodução total ou parcial do trabalho sem a autorização da Universidade, do autor e do orientador.

\section{Danrlei de Freitas Azevedo}

Professor Adjunto do Departamento de Teoria do Teatro da Universidade do Rio de Janeiro (UNIRIO). Graduou-se em Teoria do Teatro em 2002 (UNIRIO). Cursou mestrado na PUC-Rio, onde defendeu a dissertação Arte contemporânea e o sentido crítico da experiência estética no Programa de Pós-Graduação em História Social da Cultura.

Ficha Catalográfica

Azevedo, Danrlei de Freitas

Morte da arte: a aparência estética desencantada / Danrlei de Freitas Azevedo ; orientador: Luiz Costa Lima. - 2008.

266 f. ; $30 \mathrm{~cm}$

Tese (Doutorado em História)-Pontifícia Universidade Católica do Rio de Janeiro, Rio de Janeiro, 2008.

Inclui bibliografia

1. História - Teses. 2. Morte da arte. 3. Arte contemporânea. 4. Sublime. 5. Pop art. 6. Aparência estética. 7. Autonomia artística. 8. Vanguarda. I. Neves, Margarida de Souza. II. Pontifícia Universidade Católica do Rio de Janeiro. Departamento de História. III. Título. 


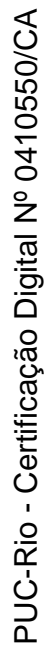

Para Maria Bela, Iago e Renata por toda a felicidade que me proporcionam 


\section{Agradecimentos}

Ao professor Luiz Costa Lima, pela atenciosa e generosa orientação, por suas aulas sempre inquietantes e valiosas. Com admiração por seu pensamento e sua obra.

Ao professor Ronaldo Brito, pelo generoso apoio, por suas instigantes reflexões e pelas excelentes aulas que cursei desde a graduação,

Agradeço ao professor Ricardo Barbosa, por suas excelentes aulas e discussões, pelo incentivo e pelas contribuições valiosas que deu a este trabalho no exame de qualificação.

Ao professor Luiz Camillo Osorio, por aceitar participar da banca, pela importante interlocução e pelas preciosas contribuições dadas ao trabalho no exame de qualificação.

Ao professor Alberto Tassinari, por generosamente aceitar participar da banca e conceder esta especial oportunidade de interlocução.

À professora Margarida de Souza Neves, Coordenadora do Programa de Pósgraduação, por toda atenção e ajuda em momentos essenciais.

Agradeço também aos professores João Masao Kamita e Paulo Pinheiro, pelo apoio e contribuição.

À Renata Schittino, pela incomparável presença, pelo diálogo fundamental.

À Giselle Leal, Daniela Pereira de Carvalho, Guido Conrado, Alexander de Moraes e Carlos Gustavo, pela amizade de longa data, pelos ótimos momentos juntos e todas as nossas conversas e discussões. 
Agradeço a Felipe Charbel e Sérgio Xavier, pela afinidade intelectual e a grande amizade de todos esses anos.

Aos demais amigos que fiz durante o doutorado. Pelo companheirismo e pelo constante debate. À Martha Telles, Olga Kempinska, Gustavo Naves, Fabrina Magalhães, Leonardo Padilha, Ana Luiza Nobre, Marcelo Rangel, Mariana Barros e todos aqueles que fizeram parte da turma.

Aos colegas professores do Departamento de Teoria do Teatro da UNIRIO, com quem muito aprendi e ainda aprendo. Sobretudo à Angela Materno, Flora Sussekind e José Da Costa. Agradeço pela valiosa interlocução.

Aos alunos que participaram de cursos que ministrei na UNIRIO, especialmente àqueles cujo interesse e estimulantes questionamentos contribuíram para o desenvolvimento de alguns temas tratados na tese.

Agradeço a Rita de Cássia Torres, pela amizade, por toda a ajuda e por sua excelente companhia.

Aos professores do doutorado em História Social da Cultura da PUC-RJ, por suas excelentes aulas. Cito Cecília Cotrim e Marcelo Gantus Jasmin que lecionaram em cursos de que tive a oportunidade de participar.

Agradeço aos funcionários da secretaria do Departamento de História da PUC-RJ, Anair, Cláudio, Cleuza, e em especial Edna Timbó- pela contribuição alegre e preciosa.

Agradeço ao CNPq pela bolsa de estudos concedida.

Finalmente, faço um agradecimento especial a meus queridos pais, Marly e Danrlei, assim como a meu irmão, Alexandre, e sua família, com quem tenho a alegria de poder sempre contar e passar ótimos momentos. 


\section{Resumo}

Azevedo, Danrlei de Freitas; Filho, Luiz de França Costa Lima. Morte da arte: a aparência estética desencantada. Rio de Janeiro, 2008, 266 p. Tese de Doutorado - Departamento de História, Pontifícia Universidade Católica do Rio de Janeiro.

O problema da morte da arte atravessa praticamente toda a história artística moderna. As preleções sobre estética de Hegel, realizadas não muito tempo depois da fundamentação kantiana de um juízo de gosto autônomo, já apresentam a idéia da dissolução da arte- a qual teria, nas palavras do filósofo, se tornado coisa do passado. Este trabalho pretende investigar a estreita e intrigante conexão entre uma arte que finalmente obteve sua autonomia na época moderna e a sombra constante de sua própria morte. Seja nos discursos estéticos que, desde os primórdios da modernidade, assinalam uma obsolescência da arte, seja no ímpeto crítico-revolucionário das vanguardas, que ensaiaram uma autodestruição da esfera artística, seja numa contemporaneidade em que parecem se apagar quaisquer distinções palpáveis entre a obra de arte e os demais produtos, entre valor estético e valor de troca, a questão da morte da arte, de um modo ou de outro, confirma sua presença. Indagar o sentido dessa longa vigência, assim como averiguar sua persistência no horizonte artístico contemporâneo, é, em resumo, a proposta da tese.

\section{Palavras-chave}

Morte da arte; arte contemporânea; sublime; pop art; aparência estética; autonomia artística; vanguarda. 


\section{Abstract}

Azevedo, Danrlei de Freitas; Filho, Luiz de França Costa Lima. Death of art: the disenchanted aesthetic appearance. Rio de Janeiro, 2008, 266 p. Tese de Doutorado - Departamento de História, Pontifícia Universidade Católica do Rio de Janeiro.

The problem of the death of the art crosses practically all modern artistic history. The Hegel's lectures Aesthetics, delivered not much later of the Kantian validation of an autonomous judgment of taste, already present the idea of the dissolution of the art- that would have, in the words of the philosopher, become thing of the past. This work intends to investigate the narrow and intriguing connection between an art that finally reached autonomy at the modern times and the constant shade of its proper death. Either in the aesthetic discourses that, since the beginning of modernity, indicate an obsolescence of the art, either in the critical-revolutionary impulse of the avant-gardes, that had fomented a selfdestruction of the artistic sphere, either in our present time, where any concrete distinctions between the work of art and other things, that is, between aesthetic value and exchange value, seems to disappear, the question of the death of the art, in one way or another, confirms its presence. To inquire the meaning of this long validity, as well as verifying its persistence in the contemporary time, is, in short, the proposal of this work.

\section{Keywords}

Death of art; contemporary art; sublime; pop art; aesthetic semblance; artistic autonomy; avant-garde. 


\section{Sumário}

1. Introdução 11

2. Fim da arte ou morte da arte? 20

2.1. Fim da história, despertar para essência $\quad 20$

2.2. Autonomia da arte: o princípio da crise 30

2.3. A obra de arte crepuscular 45

2.4. Fenômeno estético e aparição fantasmática 55

3. O sublime: negação da aparência estética, experiência de um abismo histórico $\quad 70$

3.1. Hegel e a sublime degeneração da arte 70

3.2. Traços de uma revalorização modernista do sublime 82

3.3. A dimensão da historicidade 96

3.4. Sublime, aparência abissal 106

4. Vanguarda e declínio: uma estética da finitude 124

$\begin{array}{ll}\text { 4.1. Racionalidade estética e crise das vanguardas } & 127\end{array}$

4.2. Ambigüidade da autonomia moderna 133

4.3. A dinâmica do declínio 137

4.4. Os limites do moderno em questão 144

5. A dimensão da aparência estética 151

5.1. Obra de arte e presença estética 151

5.2. Aparências estéticas e falsas presenças 163

5.3. Aparência como aparência: uma possibilidade histórica 172

5.4. Proximidade do estatuto da ficção 189

6. Fratura no modernismo: Pop art e a aparência estética mortificada 194

6.1. Pureza, planaridade, plenitude estética 196

6.2. Emancipação das particularidades sensíveis 205

6.3. Arte e vida: uma tradição estética moderna 212

6.4. Síntese modernista: negatividade estética e o princípio de morte 220

6.5. Pop art: 2 proposições $\quad 227$

$\begin{array}{ll}\text { 7. Conclusão } & 248\end{array}$

8. Referências Bibliográficas 256 
... talvez haja na arte algo que desde a origem a faça condenada, certa condição de tal modo frágil, tão distante da boa saúde que toca a moléstia incurável e a nostalgia desse estado ao qual se chega somente pela porta que conduz à morte.

Tadeusz Kantor, A morte da arte

Porém, a vida do espírito não é a que se atemoriza ante a morte e se conserva intacta da devastação, mas é a vida que suporta a morte e nela se conserva.

G. W. F. Hegel, Fenomenologia do espírito 